\title{
Presence of Salmonella AvrA in colorectal tumor and its precursor lesions in mouse intestine and human specimens
}

\author{
Rong Lu ${ }^{1}$, Maarten Bosland ${ }^{2}$, Yinglin Xia ${ }^{1,3}$, Yong-guo Zhang ${ }^{1}$, Ikuko Kato ${ }^{4}$ and Jun \\ Sun ${ }^{1}$ \\ ${ }^{1}$ Division of Gastroenterology and Hepatology, Department of Medicine, University of Illinois at Chicago, Chicago, IL, USA \\ ${ }^{2}$ Department of Pathology, University of Illinois at Chicago, Chicago, IL, USA \\ ${ }^{3}$ Division of Academic Internal Medicine and Geriatrics, Department of Medicine, University of Illinois at Chicago, Chicago, \\ $\mathrm{IL}$, USA \\ ${ }^{4}$ Department of Oncology and Pathology, Wayne State University School of Medicine, Detroit, MI, USA \\ Correspondence to: Jun Sun, email: junsun7@uic.edu \\ Ikuko Kato, email: katoi@karmanos.org
}

Keywords: colorectal cancer, inflammation, infection, IBD, Salmonella

Received: April 19, 2017 Accepted: June 26, $2017 \quad$ Published: July 06, 2017

Copyright: Lu et al. This is an open-access article distributed under the terms of the Creative Commons Attribution License 3.0 (CC BY 3.0 ), which permits unrestricted use, distribution, and reproduction in any medium, provided the original author and source are credited.

\section{ABSTRACT}

Evidence directly supporting an association between Salmonella infection and colorectal cancer in human subjects is sparse. It has been well recognized that Salmonella infection increases the risk of gallbladder cancer. AvrA, a bacterial protein from Salmonella enterica, plays a crucial role in establishing chronic infection. To our knowledge, the presence of the bacterial AvrA has never been studied in human samples. Here, we demonstrated the presence and cellular localization of AvrA in inflamed, colorectal tumor and its precursor lesions, using both animal experimental infection models and human clinical specimens. We performed a newly developed AvrA serological assay and to determine the presence of anti-Salmonella AvrA antibody in chronic infected mouse serum samples. Further, we tested the presence of AvrA gene in healthy human fecal samples, in order to advance etiological studies of Salmonella AvrA in human population. Our study suggests a potential role of this bacterial protein in human colorectal cancer. Moreover, our new serological assay may serve a useful tool to identify individuals at increased risk for colorectal cancer.

\section{INTRODUCTION}

The gastrointestinal tract is a natural habitat for a dynamic and highly competitive microbial community, which constantly contacts with the intestinal epithelial cells. Although growing evidence suggests a potential role of microbes in the development of colorectal cancer [1,2], evidence to support a direct link of intestinal bacteria to human sporadic colorectal cancer is still limited. Salmonella enterica is a Gram-negative, facultative anaerobe and an intracellular pathogen to both humans and animals, posing a major public health concern worldwide. It is estimated that more than 1 million people in the US acquire Salmonella infection annually as a foodborne illness [3]. Seroepidemiologic studies have revealed that non-typhoid Salmonella infection is much higher ( 600 times) than actually reported [4], ranging from 56 per 1000 person-years in Finland to 547 in Poland [5] and rising over years [6]. It has been well recognized long-standing Salmonella infection increases the risk of gallbladder cancer [7-9]. However, evidence directly supporting an association between Salmonella infection and colorectal cancer in human subjects is sparse.

A common aspect of infection-related cancer is the induction of chronic inflammation, which may promote DNA damage, cell proliferation and migration, through various mechanisms including epigenetic modifications $[10,11]$. Many pathogens, such as Salmonella, use type three secretion system (T3SS) to inject numerous virulence factors that induce strong proinflammatory reactions [12]. Whereas most bacteria induce inflammation in the host, some pathogenic bacteria have also evolved the abilities to temper the inflammatory response to create a suitable niche for their survival and proliferation in the host, not 
killing the host or host cells they infected. AvrA, a T3SS effector protein from Salmonella enterica, plays a crucial role in establishing chronic infection [13-15]. AvrA is a $33 \mathrm{kDa}$ protein and a close homologue to a family of acetyltransferases expressed in several enteric pathogens, including YopJ/P in Yersinia pseudotuberculosis and VopA in Vibrio parahemalyticus [15]. AvrA exerts anti-inflammatory activities through inhibition of NF- $\mathrm{B}$ and JNK pathways, resulting in reduced secretion of inflammatory mediators [16]. Furthermore, this JNK inhibition leads to suppression of apoptosis particularly in the context of proinflammatory enteropathogenic Salmonellosis [13-15], and thus to prolonged bacterial intracellular survival.

We have revealed that Salmonella AvrA possesses deubiquitination properties [12], leading to activation of the $\beta$-catenin pathway. Subsequent studies using mouse models have revealed that infection with AvrA-expressing Salmonella increased Wnt and total $\beta$-catenin expression, Wnt/ $\beta$-catenin transcriptional activity and the numbers of stem cells and of proliferative cells in infected intestinal mucosa, underscoring the role of AvrA in stem cell maintenance [17]. In the carcinogen azoxymethane (AOM)/ inflammatory agent dextran sodium sulphate (DSS) colon cancer model [18], colorectal tumor incidence indeed significantly increased in the AvrA ${ }^{+}$Salmonella infected mice, compared with mice without bacterial gavage or infected with AvrA $^{-}$Salmonella [18]. In our previous studies, we confirmed chronic colonization of AvrAexpressing Salmonella, but we have not examined the localization of AvrA protein in infected intestine and tumor.

To our knowledge, the presence of the bacterial virulence AvrA has never been studied in human samples. The primary aim of this study is to demonstrate the presence and intra-cellular localization of AvrA in inflamed, colorectal tumor and its precursor lesions in both animal experimental infection models and human clinical specimens. The secondary aims were to test performance of newly developed AvrA serological assay and to determine the presence of anti-Salmonella AvrA antibody in chronic infected mouse serum samples. Further, we tested the presence of $A v r A$ gene in healthy human fecal samples, in order to advance etiological studies of Salmonella AvrA in human population.

\section{RESULTS}

\section{Detectable anti-AvrA antibody in serum of mice 10 weeks post AvrA-positive Salmonella infection}

We developed an ELISA measurement to test the existence of anti-AvrA antibody in mice post Salmonella infection. First, combinations of different dilutions of antigen and antibodies were tested for titration. Then the assay was applied to mouse serum from the long-term experimental Salmonella infection model (Figure 1). We used anti-AvrA antibody as the positive control and 1\% BSA as a negative control in these experiments. As shown in the Figure 1, we were able to detect the significant increased AvrA antibody in mouse serum 10 weeks post AvrA-positive Salmonella infection. We could also see the significantly increased Optical density (OD) value of anti-AvrA antibody in the mice post infection 27 week in inflammation model (Figure 1A). Using samples from the Salmonella-infected mice in AOM/DSS colon cancer model [18], we were able to detect significantly high value of anti-AvrA antibody in mouse serum 45 week post Salmonella-infected (Figure 1B).
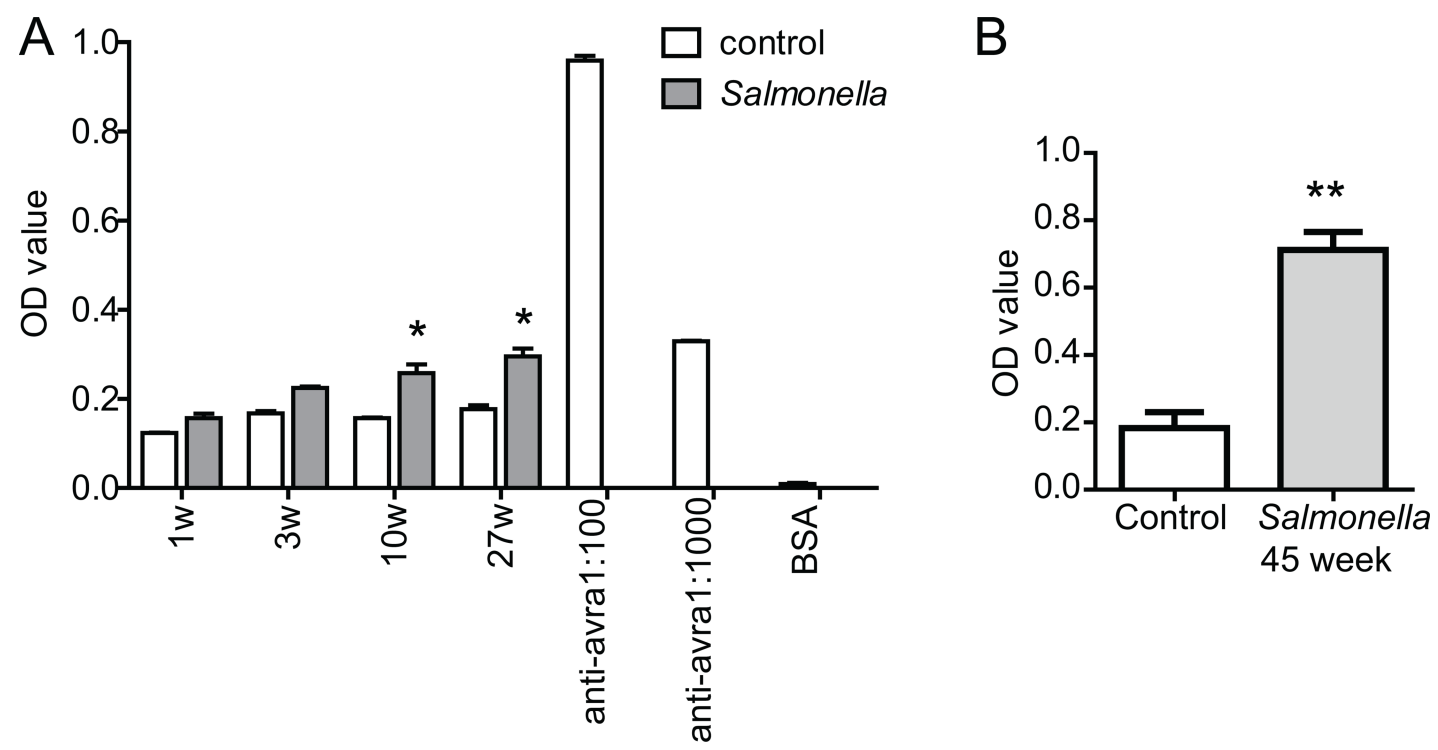

Figure 1: Elisa measurement of anti-AvrA protein in mouse serum. (A) Mice were infected with Salmonella mutant strains $\mathrm{PhoP}^{\mathrm{C}} \mathrm{AvrA} \mathrm{A}^{-} / \mathrm{AvrA}^{+}$by oral gavage. Serum anti-AvrA were measured at 1, 3, 10 and 27 weeks postinfection. (B) Anti-AvrA protein of mouse serum in colon cancer model. Serum anti-AvrA antibody was measured at in the AOM/DSS mice 45 weeks post Salmonella infection. We used anti-AvrA antibody as a positive control and 1\% BSA as a negative control. ${ }^{*} P<0.05, * * P<0.01, n=3$, by Student's $t$ test. 


\section{Location of AvrA in Salmonella infected mouse colon}

The immunohistochemistry (IHC) was used to examine the location of AvrA in Salmonella ser. Enteritids infected mouse colon post infection 8 hours and 4 days. We have samples infected with Salmonella strains with or without AvrA. The results showed the nuclear staining of AvrA (brown color) in epithelial cells in the $S$. Enteritids wild-type group (Figure 2). Strong nuclear staining of many epithelial cells and some sub-epithelial stroma were found in the $S$. Enteritids AvrA ${ }^{+}$group. In contract, no positive AvrA staining was found in the $S$. Enteritids AvrA $^{-/}$group (Figure 2).

In the Salmonella-chronically infected mouse colon, we were able to detect the positive AvrA staining in colon $1,3,10$, and 27 week post infection (Figure 3A). These data indicate the persistent expression of AvrA in the Salmonella infected colon.

\section{Presence of AvrA in colon of mouse carcinogenesis model with Salmonella expressing AvrA}

In the chemical carcinogenesis AOM/DSS model, colorectal tumor incidence indeed markedly increased in the AvrA ${ }^{+}$Salmonella infected mice, compared with mice without bacterial gavage or infected with AvrA Salmonella [18]. We found that strong nuclear staining of AvrA in the colon with tumor from AOM+DSS+ $\mathrm{PhoP}^{\mathrm{C}} \mathrm{AvrA} \mathrm{A}^{-} / \mathrm{AvrA}^{+}$mice 45 weeks post infection (Figure 3B). In contrast, no AvrA expression in tumors from mice infected $\mathrm{AOM}+\mathrm{DSS}+\mathrm{PhoP}^{\mathrm{C}} \mathrm{AvrA}{ }^{-}$group and the AOM+DSS mice without Salmonella infection. Taken together, we confirmed persistent AvrA staining in the colon infected with the AvrA-expressing Salmonella strains (Figure 3B).

\section{AvrA expression in human inflammatory bowel diseases (IBD) and colon samples}

We then examined the presence of AvrA protein in IBD and colorectal tumor tissue in human clinical samples. We found positive AvrA staining, including the nuclear staining of AvrA, in intestinal epithelial cells of the patients with IBD (Crohn's disease and ulcerative colitis). Among the 27 inflammation category cores, there were only 6 formally diagnosed IBD cases (5 Crohn's disease and 1 ulcerative colitis), the rest was annotated as chronic inflammation. Regardless, these cores present inflammatory cell infiltration. But we do not have detailed information as to whether IBD was in active stage. When we divided this group to IBD and other inflammation, mean normalized AvrA staining score was slightly higher in $\operatorname{IBD}(2.26 \pm 0.35 \mathrm{SE})$ than in the others $(1.91 \pm 0.19 \mathrm{SE})$, but the difference was not statistically significant.

The immunohistochemistry (IHC) data from human normal mucosa and cancer tissue clearly show dense red staining of AvrA in cancer tissue, including nuclei (Figure 4), whereas AvrA staining is negative in normal colon (low and high power).

\section{AvrA staining in human TMA samples}

The three TMA chosen for this study included variable numbers of colorectal histologies in different

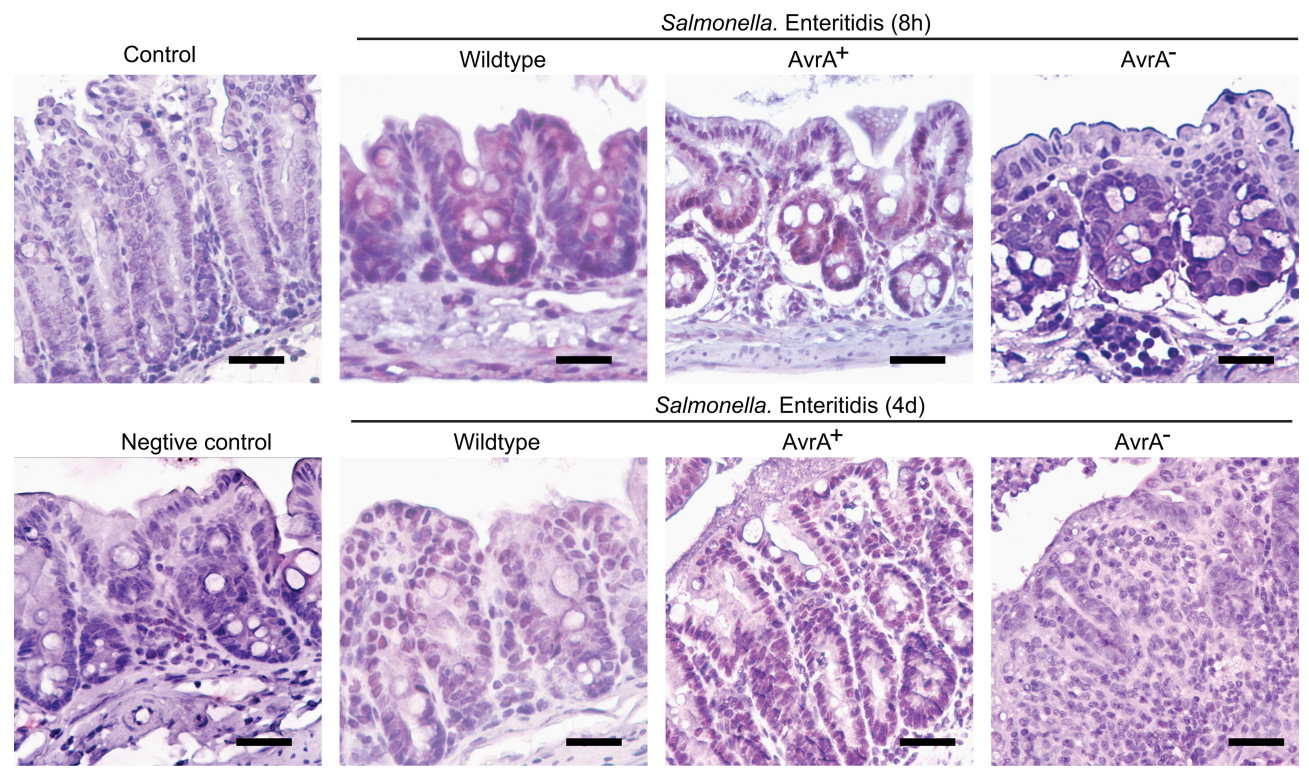

Figure 2: IHC of AvrA staining in mouse intestine infected with Salmonella Enteritidis. Mice were infected with wild-type Salmonella Enteritidis C50336, AvrA mutant S.E-AvrA ${ }^{-}$and the complemented strain S.E-AvrA ${ }^{+}$[43] by oral gavage. Immunostaining of AvrA in the mouse colon tissue 8 hour and 4 day post-Salmonella infection. $n=3$ per group. 
proportions as shown in Table 1. Approximately a half from unique colorectal cancer patients, divided into primary tumor $(n=48)$, adjacent normal mucosa $(n=13)$ and metastasized lymph nodes $(n=14)$. Another half consisted of benign lesions (34 adenoma and 27 inflammation) and normal mucosa without any colorectal pathologies $(n=19)$. As reported in Table 2, after normalization each array showed the identical mean staining score. Compared with normal mucosa without any colorectal pathology, cancer adjacent mucosa had a statistically significantly higher mean normalized staining score $(P=0.018)$, while primary tumors themselves exhibited a significantly lower mean score $(P=0.013)$. Benign lesions and lymph nodes showed equivalent staining to normal mucosa (Table 3). Interstingly, we also identified the nuclear staining of AvrA in intestinal epithelial cells of the colon cancer patients.

\section{Presence of AvrA gene in healthy human fecal samples}

We found little variation in overall bacterial $16 \mathrm{~S}$ RNA among 24 human fecal samples, but as shown in Figure 5, relative Salmonella counts, assessed by Salmonella 16S-23S internal transcribed spacer (ITS) over universal bacterial 16S RNA, varied markedly from a sample to a sample. All of these samples except three (black/dark bars, No. 18, 21, and 24) also exhibited
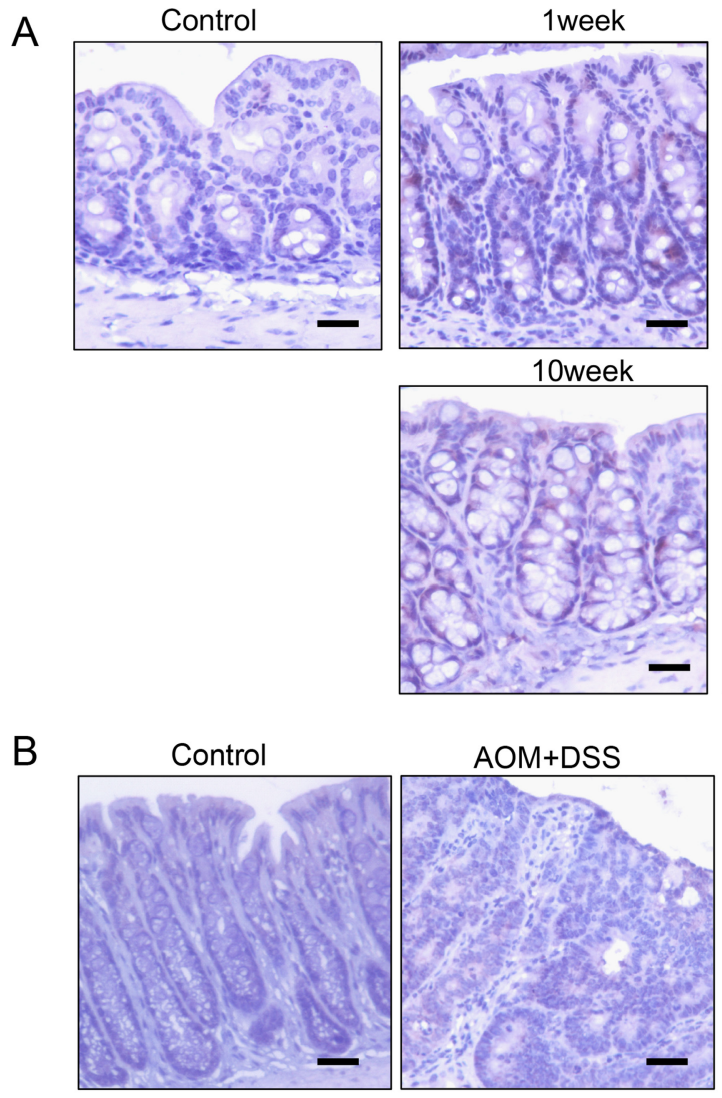

AOM+DSS+

PhoP ${ }^{\mathrm{C}}$ AvrA

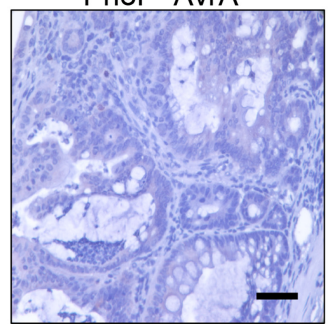

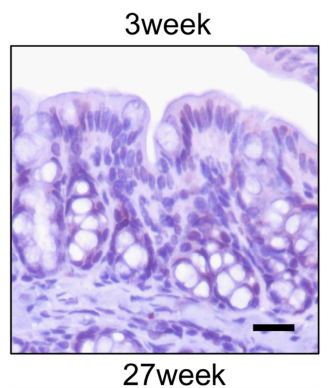
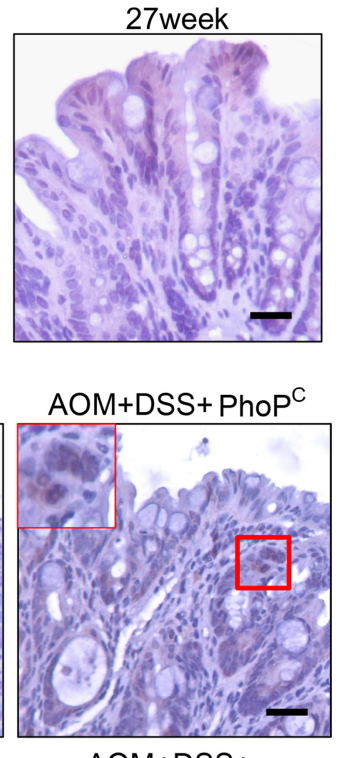

AOM+DSS+ PhoP $^{\mathrm{C}}$ AvrA $^{-} /$AvrA $^{+}$

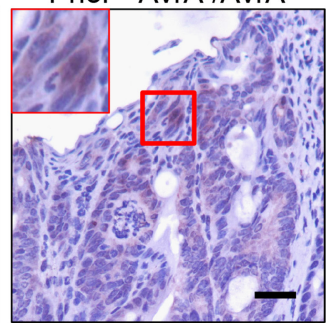

Figure 3: IHC of AvrA staining in mouse intestine with chronic infection. (A) In the Salmonella-chronically infected mouse colon, we were able to detect the positive AvrA staining in colon 1, 3, 10, and 27 week post infection. These data indicate the persistent expression of AvrA in the Salmonella infected colon. (B) AvrA in mouse intestine with chronic infection and colon cancer. Immunostaining of AvrA in colon of mouse carcinogenesis model with Salmonella expressing AvrA in the mouse colon cancer model. Scale bar $=500$ um. $n=3$ per group. 
Table 1: Distribution of colorectal pathologies of tissue cores included from 3 tissue micro arrays

\begin{tabular}{|c|c|c|c|c|c|}
\hline \multirow{2}{*}{ Pathology } & & \multicolumn{4}{|c|}{ TMA slides } \\
\hline & & CO808-036 & CO809a-C051 & BC05002a-E068 & Total \\
\hline \multirow{2}{*}{ Colon Cancer } & $N$ & 20 & 10 & 18 & 48 \\
\hline & $\%$ & 34.48 & 17.54 & 45.0 & \\
\hline \multirow{2}{*}{ Node metastasis } & $N$ & 8 & 0 & 6 & 14 \\
\hline & $\%$ & 13.79 & 0 & 15.0 & \\
\hline \multirow{2}{*}{ Cancer adjacent } & $N$ & 9 & 0 & 4 & 13 \\
\hline & $\%$ & 15.52 & 0 & 10 & \\
\hline \multirow{2}{*}{ Adenoma } & $N$ & 7 & 26 & 1 & 34 \\
\hline & $\%$ & 12.07 & 45.61 & 2.5 & \\
\hline \multirow{2}{*}{ Inflammation } & $N$ & 10 & 12 & 5 & 27 \\
\hline & $\%$ & 17.24 & 21.05 & 12.5 & \\
\hline \multirow{2}{*}{ Normal mucosa } & $N$ & 4 & 9 & 6 & 19 \\
\hline & $\%$ & 6.9 & 15.79 & 15.0 & \\
\hline Total & & 58 & 57 & 40 & 155 \\
\hline
\end{tabular}

Table 2: Raw and normalized AvrA staining scores for three TMA slides

\begin{tabular}{lllcccc}
\hline TMA name & $\boldsymbol{N}$ & AvrA scores & Mean & Median & Quartile 1 & Quartile 3 \\
\hline C0808-036 & 58 & Raw & 10.103 & 10.00 & 6.00 & 15.00 \\
& & Normalized & 1.771 & 1.77 & 1.07 & 2.57 \\
C0809a-C051 & \multirow{2}{*}{57} & Raw & 2.158 & 1.00 & 0.00 & 2.00 \\
& & Normalized & 1.771 & 1.66 & 0.66 & 2.36 \\
BC05002a-E068 & \multirow{2}{*}{40} & Raw & 1.175 & 1.00 & 0.00 & 1.00 \\
& & Normalized & 1.771 & 2.10 & 0.87 & 2.10 \\
\hline
\end{tabular}

Table 3: Mean normalized staining scores by colorectal pathology

\begin{tabular}{llccc}
\hline Pathology & $\boldsymbol{N}$ & Normalized sore mean & Standard Error & $\boldsymbol{P}$-values* \\
\hline Colon cancer & 48 & 1.372 & 0.125 & 0.0126 \\
Node Metastasis & 14 & 1.880 & 0.231 & 0.7853 \\
Cancer Adjacent & 13 & 2.719 & 0.240 & 0.0177 \\
Adenoma & 34 & 1.649 & 0.148 & 0.2070 \\
Inflammation & 27 & 1.988 & 0.166 & 0.9218 \\
Normal mucosa & 19 & 1.963 & 0.198 & - \\
\hline
\end{tabular}

*Difference from normal mucosa

amplification for Salmonella AvrA. These data are consistent with high prevalence of antibodies against Salmonella flagellin found in Metropolitan Detroit population [19].

\section{DISCUSSION}

In our current study, we, for the first time, have demonstrated the presence of Salmonella AvrA protein in colorectal mucosa from mice with experimental infection and human clinical specimens. Also, we showed the detectable anti-AvrA-antibody in mouse serum post Salmonella infection by ELISA. Using IHC, we found the distribution AvrA in Salmonella infected mouse colon and in Salmonella-infected mice with colon cancer. Furthermore, we reported the presence of AvrA protein in inflammatory bowel disease and colorectal tumor tissue in human clinical samples. Human fecal samples exhibited amplification for Salmonella AvrA. Our study suggests a novel role of bacterial protein associated with colon cancer. 
Our IHC data of anti-AvrA showed that AvrA is more commonly found in adjacent mucosa than primary tumors. It is not necessarily unexpected that pathogens are less commonly detected in cancer tissue than adjacent normal mucosa. The presence of bacteria may no longer be necessary once carcinogenic pathways are activated, as seen in the case of gastric cancer where $H$ Pylori is less frequently detected in advanced premalignant lesions than in less advanced lesions [20]. Furthermore alteration of cell surface glycosylation is often found in various cancers [21] and it also influences intestinal microbial composition [22]. Recently an enzyme catalyzing glycosylation, B4GALNT2, has been associated with increased susceptibility to Salmonella infection [23], while its expression has been reported to be downregulated in colon cancer compared with normal mucosa [24]. These findings well corroborate our observation that more AvrA is found in adjacent mucosa than in primary tumors.

AvrA gene is present in most Salmonella enterica isolates from humans and animals. This is particularly the case for non-typhoid Salmonella as its prevalence gene was reported to be $98-100 \%(514 / 523$ and185/185) $[25,26]$,
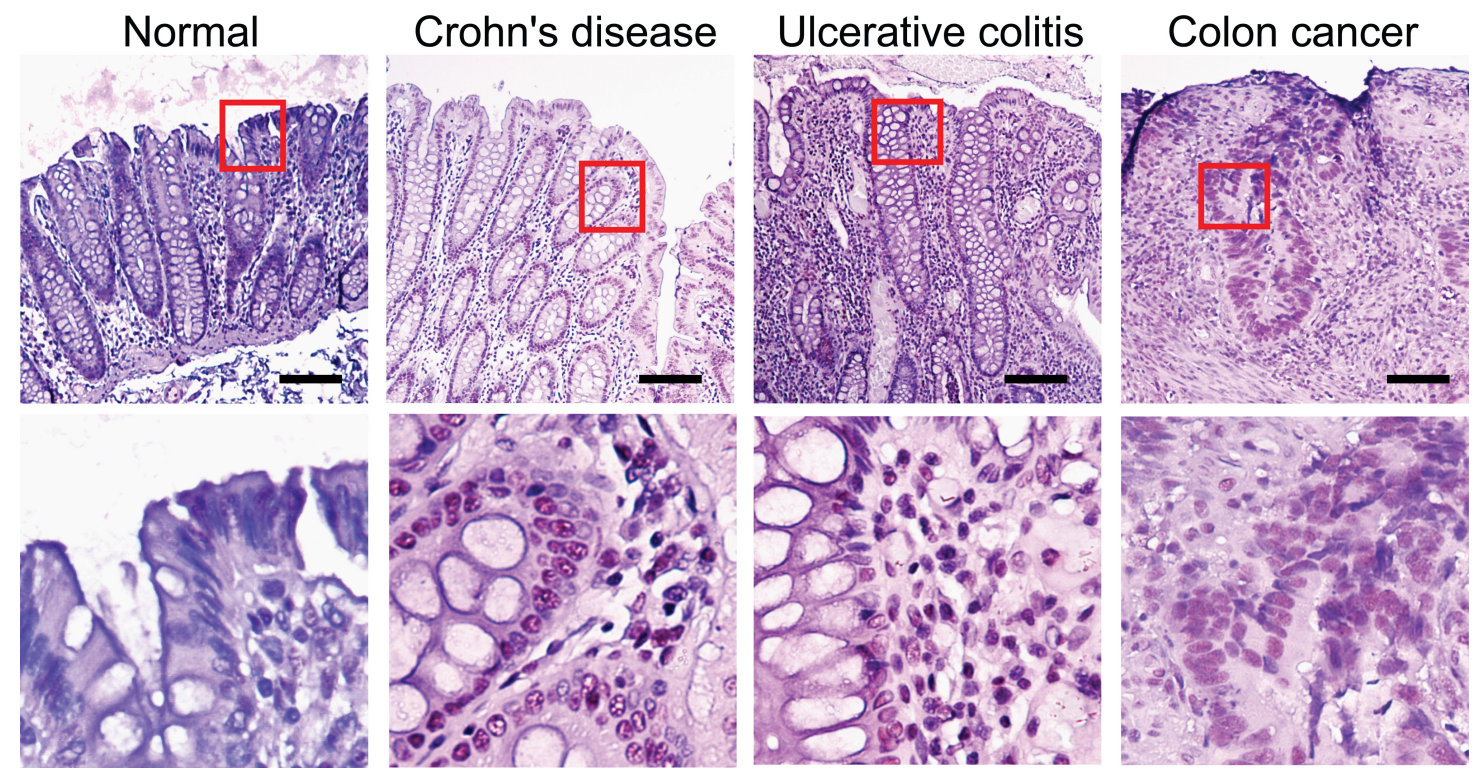

Figure 4: IHC of AvrA staining in human tissue of IBD and colon cancer. Immunostaining of AvrA in human normal, IBD and colon tumor tissue. Scale bar $=100$ um.

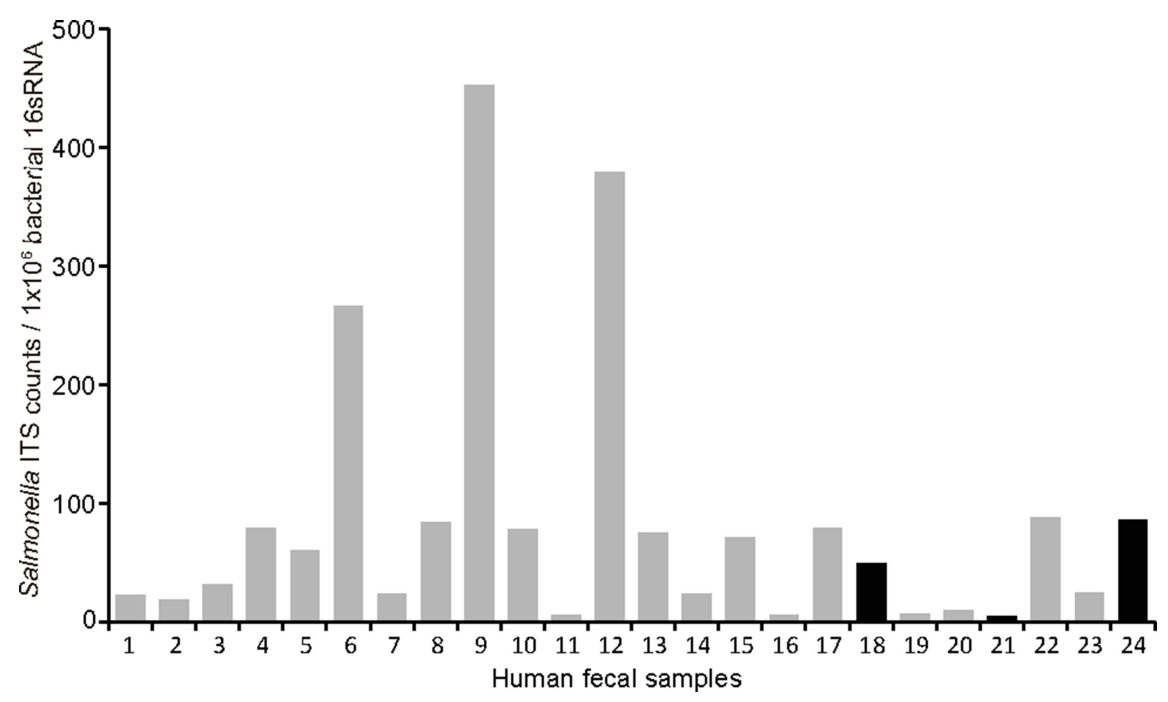

Figure 5: Amplification for Salmonella AvrA in human fecal samples. Human DNA samples $(n=24)$ were amplified using realtime PCR. We applied primers for universal bacterial 16sRNA, Salmonella 16S-23S internal transcribed spacer (ITS), as well as Salmonella AvrA. We found little variation in overall bacterial 16S RNA, relative Salmonella counts, assessed by ITS over universal bacterial 16S RNA, varied markedly from a sample to a sample. All of these samples except three (black/dark bars) also exhibited amplification for Salmonella AvrA. 
while it was absent in typhoid strains. On the contrary, AvrA protein expression is known to vary markedly with clinical presentation. AvrA protein is not often produced by clinical isolates from systemic disease, but it is often detectable in those from limited enteritis [27]. Our data of AvrA presence in the colon of chronically infected mice indicate the persistent function of bacterial proteins in the host. It is now clear that expression of AvrA is regulated in a post-transcriptional manner and that mRNA transcription takes place constitutively in all AvrA-positive strains [28], as AvrA remains silent when cloned into E. coli [29]. In fact, a number of proteobacterial pathogens have evolved global regulation systems of posttranscriptional gene expression for their various virulence factors to be responsive to changes in the environment and to flourish in specialized host niches and Salmonella enterica is equipped with Csr (carbon storage regulator) system, consisting of a small RNA binding protein (CrsA) and non-coding RNAs (CsrB/CsrC) [30]. CsrA binding to the 5' untranslated and/or early coding regions of mRNAs alters mRNA translation, turnover and/or transcript elongation, leading to either decay or stabilization of specific mRNA targets, while $\mathrm{CsrB} / \mathrm{CsrC}$ containing multiple CsrA binding sites bind and sequester CsrA, thereby antagonizing CsrA activities [30, 31]. Kerrinnes et al. [28] demonstrated that overexpression of either CsrA or CsrB shut down AvrA expression, but that constitutional CsrA expression was required for AvrA expression. These posttranscriptional controls of AvrA highlight the need to study its protein levels rather than nuclei acid levels.

The location of AvrA is shown in both cytosol and nuclei. Previous studies discovered deubiquitinase and acetyltransferase properties of AvrA leading to upregulation of the beta-catenin signaling pathway and modifying p53 activities [14, 15, 18], which are critical in initiation and progression of colorectal cancer. Ubiquitination and deubiquitination are in fact major host targets of human oncoviruses, including HPV, KSHV, EBV, HTLV1 and adenovirus [32]. Known host targets of AvrA O (threonine)- and $\mathrm{N}^{\varepsilon}$ (lysine)-acetylation include MAPKK [13] and p53 [12, 33]. Acetylation of critical amino acid residues in MAPKK blocks MAPKK phosphorylation activities, thus inhibits downstream c-Jun N-terminal kinase and NF- $\kappa \mathrm{B}$ signaling pathways [12]. This may in turn compensatedly activate STAT3 signaling and inflammation, as shown in mouse model of AvrA induced colorectal carcinogenesis [34]. On the other hand, p53 acetylation has been shown to increase its stability and transcriptional activities [35]. Separately from the role of AvrA effector in intestinal epithelial cells, Salmonella SopB, another effector from the same pathogenicity island, transforms primed epithelial cells into $\mathrm{M}$ cells to promote host colonization and invasion [36] The autocrine activation of RelBexpressing FAE enterocytes by up-regulated RANKL/ RANK further guides the EMT-regulating transcription factor Slug that marks epithelial transdifferentiation into $\mathrm{M}$ cells. Based on these observations and our current data, AvrA may play a novel role through posttranslational modifications associated with colon cancer. It is still not known how AvrA moves to the nuclei and interacts with host genes/proteins.

We previously reported that antibody against Salmonella flagellin was higher in colorectal cancer and pre-cancer cases than in controls in two distinct populations in US and the Netherlands and that smoking and dietary intake (i.e., iron) is one of the mediating factors, suggesting a possible link of Salmonella to colorectal cancer [19]. Yet, information is still limited regarding frequencies of sustained Salmonella infection after initial acquisition in the population. It is not clear that how AvrA plays its role in the human colon cancer. In our previous study, we found that AvrA can activate the beta-catenin pathway in human colon cancer cells, such as Caco2-BBE and HCT 116 [12, 14]. Our unpublished data also indicate the overlapping of nuclear staining of AvrA and $\beta$-catenin in samples from human colon cancer. We will investigate whether bacterial AvrA exploits host posttranslational modification of key proteins, such as $\beta$-catenin, in oncogenic pathways to promote cell proliferation and colorectal tumorigenesis in the future studies.

To our knowledge, this is the first to report the presence of Salmonella AvrA protein in human tissue specimens as well as that antibodies against AvrA are in fact detectable in infected hosts. The latter finding will prompt studies to investigate whether human subjects infected with AvrA-expressing Salmonella have an increased risk of developing colorectal cancer using prediagnostic sera from prospective cohorts.

\section{MATERIALS AND METHODS}

\section{Human samples}

Human fecal DNA samples used for this study were a part of deidentified samples from the previous study where stool specimens were collected in RNA later from non-cancer volunteers in Metropolitan Detroit. Details concerning the parent study have been reported elsewhere [37-40]. The human tissue microarray (TMAs) used in our studied were purchased from US Biomax, Inc. (Biomax, Derwood, MD), and stained as described previously $[14,18,41,42]$.

\section{Animals and ethics statement}

C57BL/6 mice (Female, 6-8 weeks old) were obtained from the Jackson Laboratory (Jackson Laboratory, Bar Harbor, ME, USA). All animal work was approved by University of Rochester and University of Illinois at Chicago Committee on Animal Resources. Euthanasia was accomplished via sodium pentobarbital 
(100 mg per $\mathrm{kg}$ body weight) I.P., followed by cervical dislocation. All methods were carried out in accordance with the approved guidelines by Committees on Animal Resources.

\section{Bacterial strains and growth condition}

Salmonella strains used in this study included Salmonella mutant strains $\mathrm{PhoP}^{\mathrm{C}} \mathrm{AvrA}^{-} / \mathrm{AvrA}^{+}$, wild-type Salmonella Enteritidis C50336, AvrA mutant S.E-AvrAand the complemented strain S.E-AvrA ${ }^{+}$(Table 4 [43]). Bacterial cultures were prepared by inoculating $10 \mathrm{ml}$ of Luria-Bertani broth with $0.01 \mathrm{ml}$ of a stationary-phase culture followed by overnight incubation $(>18 \mathrm{~h})$ at $37^{\circ} \mathrm{C}$, as previously described $[41,44]$.

\section{Real-time PCR of bacteria 16sRNA and Salmonella}

Real-time PCR was used to amplify universal bacterial 16sRNA, Salmonella 16S-23S internal transcribed spacer, as well as Salmonella AvrA. Total DNA was extracted from human fecal Qiagen Stool Kit (Qiagen,Hilden, Germany and DNA was then subjected to real-time PCR (SYBR Green PCR kit, BioRad) with primers (Table 5). Percent expression was calculated as the ratio of the normalized value of each sample relative to that of the corresponding control group. All real-time PCR reactions were performed in triplicate.

\section{Salmonella-infected mouse model}

Animal experiments were performed using specific pathogen-free female C57BL/6 mice. Water and food were withdrawn $4 \mathrm{~h}$ before oral gavage with $7.5 \mathrm{mg} / \mathrm{mouse}$ of streptomycin (100 $\mathrm{ml}$ of sterile solution). Afterwards, animals were supplied with water and food ad libitum. Twenty hours after streptomycin treatment, water and food were withdrawn again for $4 \mathrm{~h}$ before the mice were infected with $1 \times 10^{6}$ colony-forming units of Salmonella (100-ml suspension in HBSS (Hank's Balanced Salt Solution) or treated with sterile HBSS (control) by oral gavage as previously described [41, 44]. After Salmonella gavage, tissue samples were collected at $8 \mathrm{~h}$ and 4 days for short term model and at 1, 3, 10, 27 weeks for Salmonellachronically infected model.

\section{Salmonella infected colon cancer mouse model}

Animal experiments were performed by using specific pathogen-free female C57BL/6 mice (Taconic) that were 6-7 weeks old, as previously described [45] Water and food were withdrawn $4 \mathrm{~h}$ before oral gavage with $7.5 \mathrm{mg} / \mathrm{mouse}$ of streptomycin $(100 \mu \mathrm{l}$ of sterile solution). Afterwards, animals were supplied with water and food ad libitum. Twenty hours after streptomycin treatment, water and food were withdrawn again for four hours before the mice were infected with $1 \times 10^{6} \mathrm{CFU}$ of $S$. typhimurium (100- $\mu$ l suspension in HBSS) or treated with sterile HBSS (control) by oral gavage, as previously described [46] After Salmonella gavage, AOM/DSS were administrated as follows: azoxymethane (AOM), $10 \mathrm{mg} / \mathrm{kg}$ body weight, intraperitoneal injection, 1\% dextran sodium sulfate (DSS) in drinking water. At 45 weeks after Salmonella infection, tissue samples were collected.

\section{Immunohistochemistry}

Intestinal tissues were freshly collected and embedded in paraffin wax after fixation with a $10 \%$ neutral buffered formalin. Immunohistochemistry was performed on paraffin-embedded sections $(4 \mu \mathrm{m})$ of colons. After preparation of the slides as described previously $[14,18,41,42]$ slides were incubated in 3\% hydrogen peroxide for 20 minutes at room temperature to block endogenous peroxidase activity, followed by incubation for 60 minutes in $2 \% \mathrm{BSA}$ in PBS to reduce nonspecific background. The slides were incubated with anti-AvrA antibody at $4{ }^{\circ} \mathrm{C}$ overnight. Samples were then incubated with goat anti-rabbit antibody (Jackson ImmunoResearch, West Grove, PA, USA) for 1 hour at room temperature. Anti-AvrA antibody was custom-made as previously described) [33].

\section{Salmonella anti-AvrA antibody enzyme-linked immunosorbent assay}

Salmonella AvrA antibody in mouse serum was measured using an AvrA antibody enzyme-linked immunosorbent assay. The 96-well plate was coated with AvrA protein $(1 \mu \mathrm{g} / \mathrm{ml}) 4^{\circ}$ overnight. Salmonella AvrA protein was purified in Sun lab [33]. The coated plate was blocked with $1 \%$ BSA $4^{\circ}$ overnight. Mouse serum (100 ul per well, 1:5 dilution) were added to the well for $2 \mathrm{~h}$ in $37^{\circ}$ incubator. Following complete washing, add 1:300 diluted HRP-conjugated Goat anti-mouse antibody (Bio-rad, Hercules, CA) to each well for $1 \mathrm{~h}$ in $37^{\circ}$. Following complete washing, KPL SureBlue peroxidase substrate was added. Measure the absorbance of each well at $450 \mathrm{~nm}$. We used anti-AvrA antibody (1:100\&1:1000) as positive control and $1 \% \mathrm{BSA}$ as negative control. The anti-AvrA antibody was custom-made and used in our previous studies for Western blots [47]. The 15 amino acid [36] peptide CGEEPFLPSDKADRY was designed based on the AvrA sequence aa\#216-230 (GenBank accession no. AE008830).

\section{Statistical analysis}

Generally, descriptive statistics for continuous variables were expressed as mean \pm standard deviation (SD), categorical variables were presented as frequency 
Table 4: Salmonella strains used in the current study

\begin{tabular}{|c|c|c|}
\hline Strains & Characteristics & References \\
\hline S.E-WT & Salmonella Enteritidis wild type CMCC(B)50336 & {$[43]$} \\
\hline S.E- AvrA- & C50336 AvrA-deficient mutant & {$[43]$} \\
\hline S.E- AvrA ${ }^{+}$ & C50336 AvrA-deficient mutant carrying pBR322-AvrA & {$[43]$} \\
\hline $\mathrm{PhoP}^{\mathrm{C}}$ & $\begin{array}{l}\text { Non-pathogenic complex regulator mutant derived from } \\
\text { wild-type SL14028 }\end{array}$ & {$[18,41]$} \\
\hline $\mathrm{PhoP}^{\mathrm{C}} \mathrm{AvrA}{ }^{-}$ & AvrA- mutation derived from $\mathrm{PhoP}^{\mathrm{C}}$ & {$[18,41]$} \\
\hline $\mathrm{PhoP}^{\mathrm{C}} \mathrm{AvrA}{ }^{-} / \mathrm{AvrA}^{+}$ & PhoP $^{\mathrm{C}}$ AvrA- with complemented plasmid encoding AvrA & {$[18,41]$} \\
\hline
\end{tabular}

Table 5: Primers for real-time PCR

\begin{tabular}{ll}
\hline Name & sequence $\mathbf{5}^{\prime}-\mathbf{3}^{\prime}$ \\
\hline Univ bacteria $16 \mathrm{~s} \mathrm{~F}$ & TCCTACGGGAGGCAGCAGT \\
Univ bacteria $16 \mathrm{~s}$ R & GGACTACCAGGGTATCTAATCCTGTT \\
Salmonella ITS F & TATGCCCCATCGTGTAGTCAGAAC \\
Salmonella ITS R & TGCGGCTGGATCACCTCCTT \\
Salmonella AvrA F & GAATGGAAGGCGTTGAATCTGC \\
Salmonella AvrA R & GTTGTGCGCCTTGAGTATGTTTGTAA \\
\hline
\end{tabular}

and proportion. For AvrA staining scores, mean, median, and quartile were reported. All statistical tests were two sided. $P$ values of 0.05 or less were considered statistically significant.

Data were expressed as mean $\pm \mathrm{SD}$ in Elisa assay (Figure 1). Differences between Salmonella and control groups were analyzed by Student's $t$ test with GraphPad Prism 5.

The TMAs were scored by a single well trained veterinarian pathologist who has more than 30 years of experience (Dr. Maarten Bosland, Professor of Department of Pathology, UIC). IHC of AvrA staining was initially assessed as a product of staining intensity $(0,1$, 2, 3, $4=$ no staining, minimal, slight, moderate, marked intensity) and percentage of cells stained (1, 2, 3, 4, $5=$ few scattered (occasional cells), several scattered cells, focal (one or a few areas or cells), multifocal (several areas of cells), diffuse (most cells), ranging from 0 to 20. Out of the 168 cores scored on three TMA slides, hyperplasia $(n=8)$ was excluded due to too small sample size as a single diagnostic category. Further we took only one of the cores with the highest staining score for the 5 paired samples derived from same patients present within the same TMA slides. As a result, the final analytical sample consisted of 155 unique cores. The compassion of the results of the three TMA slides revealed substantial staining variability among slides, specifically generally much stronger staining in the 1 st slide, much weaker in the 2 nd and even weaker in the $3 \mathrm{rd}$. Thus, to combine results from three TMA slides, we calculated normalized staining scores based on relative rankings of individual core staining within each slide using method described by
Blom [48], which generates normalized scores centered at 0 . To make all scores positive, each score was added to the lowest score among all TMAs. As a result, the final normalized scores ranged from 0 to 4 . These results were summarized on Table 2. Then, analysis of variance was used to test differences in mean normalized scores across 5 different colorectal pathologies (inflammation, adenoma, cancer adjacent mucosa, colorectal cancer and metastasized lymph nodes) from normal mucosa. The statistical analyses were conducted by SAS version 9.4 (SAS Institute Inc., Cary, NC, USA).

\section{Authors' contributions}

Rong Lu and Yongguo Zhang: Design and perform experiments, prepare figures, interpretation of the data, and preparation and revision of the manuscript. Maarten Bosland: IHC and pathological analysis, interpretation of the data, and revision of the manuscript. Yinglin Xia: Statistical analysis, interpretation of the data, and preparation and revision of the manuscript. Ikuko Kato: Conception of the study, sample acquisition, statistical analysis, interpretation of the data, and preparation and revision of the manuscript. Jun Sun: Conception and design of the study, interpretation of the data, writing and revision of the manuscript, getting fund to support the research.

\section{ACKNOWLEDGMENTS AND FUNDING}

We would like to acknowledge the National Institutes of Health/NIDDK grant R01 DK105118 to Jun Sun and UIC Cancer Center for supporting her research. 


\section{CONFLICTS OF INTEREST}

There are no conflicts of interest.

\section{REFERENCES}

1. Joossens M, Huys G, Cnockaert M, De Preter V, Verbeke K, Rutgeerts P, Vandamme P, Vermeire S. Dysbiosis of the faecal microbiota in patients with Crohn's disease and their unaffected relatives. Gut. 2011; 60:631-7. https://doi. org/10.1136/gut.2010.223263.

2. Marchesi JR, Dutilh BE, Hall N, Peters WH, Roelofs R, Boleij A, Tjalsma H. Towards the Human Colorectal Cancer Microbiome. PLoS ONE. 2011; 6:e20447. https://doi. org/10.1371/journal.pone.0020447.

3. Cianflone NFC. Salmonellosis and the GI Tract: More than Just Peanut Butter. Current gastroenterology reports. 2008; $10: 424-31$.

4. Kuhn KG, Falkenhorst G, Ceper TH, Dalby T, Ethelberg S, Molbak K, Krogfelt KA. Detecting non-typhoid Salmonella in humans by ELISAs: a literature review. J Med Microbiol 2012; 61:1-7. https://doi.org/10.1099/jmm.0.034447-0.

5. Falkenhorst G, Simonsen J, Ceper TH, van Pelt W, de Valk H, Sadkowska-Todys M, Zota L, Kuusi M, Jernberg C, Rota MC, van Duynhoven YT, Teunis PF, Krogfelt KA, Mølbak K. Serological cross-sectional studies on salmonella incidence in eight European countries: no correlation with incidence of reported cases. BMC Public Health. 2012; 12:523. https://doi.org/10.1186/1471-2458-12-523.

6. Simonsen J, Strid MA, Mølbak K, Krogfelt KA, Linneberg A, Teunis P. Sero-epidemiology as a tool to study the incidence of Salmonella infections in humans. Epidemiology and Infection. 2008; 136:895-902. https:// doi.org/10.1017/S0950268807009314.

7. Gonzalez-Escobedo G, La Perle KM, Gunn JS. Histopathological Analysis of Salmonella Chronic Carriage in the Mouse Hepatopancreatobiliary System. PLoS ONE. 2013; 8:e84058. https://doi.org/10.1371/journal. pone. 0084058 .

8. Gradel KO, Nielsen HL, Schonheyder HC, Ejlertsen T, Kristensen B, Nielsen H. Increased short- and long-term risk of inflammatory bowel disease after salmonella or campylobacter gastroenteritis. Gastroenterology. 2009; 137:495-501. https://doi.org/10.1053/j.gastro.2009.04.001.

9. Kumar S. Infection as a risk factor for gallbladder cancer. $\mathbf{J}$ Surg Oncol. 2006; 93:633-9. https://doi.org/10.1002/jso.20530.

10. Kuper H, Adami HO, Trichopoulos D. Infections as a major preventable cause of human cancer. Journal of Internal Medicine. 2000; 248:171-83. https://doi.org/10.1046/ j.1365-2796.2000.00742.x.

11. Merchant JL. Inflammation, Atrophy, Gastric Cancer: Connecting the Molecular Dots. Gastroenterology. 2005; 129:1079-82. http://dx.doi.org/10.1053/j.gastro.2005.07.038.
12. Sun J. Pathogenic Bacterial Proteins and their Anti-Inflammatory Effects in the Eukaryotic Host. Anti-inflammatory \& anti-allergy agents in medicinal chemistry. 2009; 8:214-27. https://doi. org/10.2174/187152309789151986.

13. Jones RM, Wu H, Wentworth C, Luo L, Collier-Hyams L, Neish AS. Salmonella AvrA Coordinates Suppression of Host Immune and Apoptotic Defenses via JNK Pathway Blockade. Cell Host \& Microbe. 2008; 3:233-44. http:// dx.doi.org/10.1016/j.chom.2008.02.016.

14. Ye Z, Petrof EO, Boone D, Claud EC, Sun J. Salmonella effector AvrA regulation of colonic epithelial cell inflammation by deubiquitination. Am J Pathol. 2007; 171:882-92.

15. Wu H, Jones RM, Neish AS. The Salmonella effector AvrA mediates bacterial intracellular survival during infection in vivo. Cellular Microbiology. 2012; 14:28-39. https://doi. org/10.1111/j.1462-5822.2011.01694.x.

16. Liu X, Lu R, Xia Y, Wu S, Sun J. Eukaryotic signaling pathways targeted by Salmonella effector protein AvrA in intestinal infection in vivo. BMC Microbiol. 2010; 10:326. https://doi.org/10.1186/1471-2180-10-326.

17. Liu $\mathrm{X}, \mathrm{Lu} \mathrm{R}, \mathrm{Wu} \mathrm{S}$, Sun J. Salmonella regulation of intestinal stem cells through the Wnt/ $\beta$-catenin pathway. FEBS Letters. 2010; 584:911-6. http://dx.doi.org/10.1016/j. febslet.2010.01.024.

18. Lu R, Wu S, Zhang YG, Xia Y, Liu X, Zheng Y, Chen H, Schaefer KL, Zhou Z, Bissonnette M, Li L, Sun J. Enteric bacterial protein AvrA promotes colonic tumorigenesis and activates colonic beta-catenin signaling pathway. Oncogenesis. 2014; 3:e105. https://doi.org/10.1038/ oncsis.2014.20.

19. Kato I, Boleij A, Kortman GA, Roelofs R, Djuric Z, Severson RK, Tjalsma H. Partial associations of dietary iron, smoking and intestinal bacteria with colorectal cancer risk. Nutr Cancer. 2013; 65:169-77. https://doi.org/10.108 0/01635581.2013.748922.

20. Muñoz N, Kato I, Peraza S, Lopez G, Carrillo E, Ramirez H, Vivas J, Castro D, Sanchez V, Andrade O, Buiatti E, Oliver W. Prevalence of precancerous lesions of the stomach in Venezuela. Cancer Epidemiology Biomarkers \& Prevention. 1996; 5:41-6.

21. Christiansen MN, Chik J, Lee L, Anugraham M, Abrahams JL, Packer NH. Cell surface protein glycosylation in cancer. Proteomics. 2014; 14:525-46. https://doi.org/10.1002/pmic.201300387.

22. Staubach F, Kunzel S, Baines AC, Yee A, McGee BM, Backhed F, Baines JF, Johnsen JM. Expression of the bloodgroup-related glycosyltransferase B4galnt2 influences the intestinal microbiota in mice. ISME J. 2012; 6:1345-55.

23. Rausch P, Steck N, Suwandi A, Seidel JA, Künzel S, Bhullar K, Basic M, Bleich A, Johnsen JM, Vallance BA, Baines JF, Grassl GA. Expression of the Blood-GroupRelated Gene B4galnt2 Alters Susceptibility to Salmonella 
Infection. PLoS Pathogens. 2015; 11:e1005008. https://doi. org/10.1371/journal.ppat.1005008.

24. Groux-Degroote S, Wavelet C, Krzewinski-Recchi MA, Portier L, Mortuaire M, Mihalache A, Trinchera M, Delannoy P, Malagolini N, Chiricolo M, Dall'Olio F, Harduin-Lepers A. B4GALNT2 gene expression controls the biosynthesis of Sda and sialyl Lewis X antigens in healthy and cancer human gastrointestinal tract. The International Journal of Biochemistry \& Cell Biology. 2014; 53:442-9. http://dx.doi.org/10.1016/j.biocel.2014.06.009.

25. Huehn S, La Ragione RM, Anjum M, Saunders M, Woodward MJ, Bunge C, Helmuth R, Hauser E, Guerra B, Beutlich J, Brisabois A, Peters T, Svensson L, et al. Virulotyping and Antimicrobial Resistance Typing of Salmonella enterica Serovars Relevant to Human Health in Europe. Foodborne Pathogens and Disease. 2009; 7:523-35. https://doi.org/10.1089/fpd.2009.0447.

26. Prager R, Mirold S, Tietze E, Strutz U, Knüppel B, Rabsch W, Hardt WD, Tschäpe H. Prevalence and polymorphism of genes encoding translocated effector proteins among clinical isolates of Salmonella enterica. International Journal of Medical Microbiology. 2000; 290:605-17. http://dx.doi. org/10.1016/S1438-4221(00)80009-0.

27. Streckel W, Wolff AC, Prager R, Tietze E, Tschäpe H. Expression profiles of effector proteins SopB, SopD1, SopE1, and AvrA differ with systemic, enteric, and epidemic strains of Salmonella enterica. Molecular Nutrition \& Food Research. 2004; 48:496-503. https://doi.org/10.1002/ mnfr.200400035.

28. Kerrinnes T, Zelas ZBB, Streckel W, Faber F, Tietze E, Tschäpe H, Yaron S. CsrA and CsrB are required for the post-transcriptional control of the virulence-associated effector protein AvrA of Salmonella enterica. International Journal of Medical Microbiology. 2009; 299:333-41. http:// dx.doi.org/10.1016/j.ijmm.2008.09.001.

29. Ben-Barak Z, Streckel W, Yaron S, Cohen S, Prager R, Tschäpe H. The expression of the virulence-associated effector protein gene avrA is dependent on a Salmonella enterica-specific regulatory function. International Journal of Medical Microbiology. 2006; 296:25-38. http://dx.doi. org/10.1016/j.ijmm.2005.08.004.

30. Timmermans J, Van Melderen L. Post-transcriptional global regulation by CsrA in bacteria. Cellular and Molecular Life Sciences. 2010; 67:2897-908. https://doi.org/10.1007/s00018010-0381-z.

31. Vakulskas CA, Potts AH, Babitzke P, Ahmer BMM, Romeo T. Regulation of Bacterial Virulence by Csr (Rsm) Systems. Microbiology and Molecular Biology Reviews. 2015; 79:193-224. https://doi.org/10.1128/mmbr.00052-14.

32. Shackelford J, Pagano JS. Tumor Viruses and Cell Signaling Pathways: Deubiquitination versus Ubiquitination. Molecular and Cellular Biology. 2004; 24:5089-93. https:// doi.org/10.1128/MCB.24.12.5089-5093.2004.

33. Wu S, Ye Z, Liu X, Zhao Y, Xia Y, Steiner A, Petrof EO, Claud EC, Sun J. Salmonella typhimurium infection increases p53 acetylation in intestinal epithelial cells. American Journal of Physiology. 2010; 298:G784-G94. https://doi.org/10.1152/ajpgi.00526.2009.

34. Lu R, Wu S, Zhang YG, Xia Y, Zhou Z, Kato I, Dong H, Bissonnette M, Sun J. Salmonella Protein AvrA Activates the STAT3 Signaling Pathway in Colon Cancer. Neoplasia (New York, NY). 2016; 18:307-16. https://doi.org/10.1016/j. neo.2016.04.001.

35. Reed SM, Quelle DE. p53 Acetylation: Regulation and Consequences. Cancers. 2015; 7:30-69. https://doi. org/10.3390/cancers7010030.

36. Tahoun A, Mahajan S, Paxton E, Malterer G, Donaldson DS, Wang D, Tan A, Gillespie TL, O'Shea M, Roe AJ, Shaw DJ, Gally DL, Lengeling A, et al. Salmonella transforms follicle-associated epithelial cells into $\mathrm{M}$ cells to promote intestinal invasion. Cell Host Microbe. 2012; 12:645-56. https://doi.org/10.1016/j.chom.2012.10.009.

37. Yu YJ, Majumdar AP, Nechvatal JM, Ram JL, Basson MD, Heilbrun LK, Kato I. Exfoliated cells in stool: a source for reverse transcription-PCR-based analysis of biomarkers of gastrointestinal cancer. Cancer Epidemiol Biomarkers Prev. 2008; 17:455-8. https://doi.org/10.1158/1055-9965.epi-072515.

38. Nechvatal JM, Ram JL, Basson MD, Namprachan P, Niec SR, Badsha KZ, Matherly LH, Majumdar AP, Kato I. Fecal collection, ambient preservation, and DNA extraction for PCR amplification of bacterial and human markers from human feces. J Microbiol Methods. 2008; 72:124-32. https://doi.org/10.1016/j.mimet.2007.11.007.

39. Kato I, Badsha KZ, Land S, Nechvatal JM, Matherly LH, Tarca AL, Majumdar AP, Basson MD, Ram JL. DNA/ RNA markers for colorectal cancer risk in preserved stool specimens: a pilot study. Tumori. 2009; 95:753-61.

40. Kato I, Nechvatal JM, Dzinic S, Basson MD, Majumdar AP, Ram JL. Smoking and other personal characteristics as potential predictors for fecal bacteria populations in humans. Med Sci Monit. 2010; 16:CR1-7.

41. Lu R, Liu X, Wu S, Xia Y, Zhang YG, Petrof EO, Claud EC, Sun J. Consistent activation of the beta-catenin pathway by Salmonella type-three secretion effector protein AvrA in chronically infected intestine. Am J Physiol Gastrointest Liver Physiol. 2012; 303:G1113-25. https:// doi.org/10.1152/ajpgi.00453.2011.

42. Liu X, Lu R, Wu S, Sun J. Salmonella regulation of intestinal stem cells through the Wnt/beta-catenin pathway. FEBS Lett. 2010; 584:911-6. https://doi.org/10.1016/j. febslet.2010.01.024.

43. Lin Z, Zhang YG, Xia Y, Xu X, Jiao X, Sun J. Salmonella enteritidis Effector AvrA Stabilizes Intestinal Tight Junctions via the JNK Pathway. J Biol Chem. 2016; 291:26837-49. https://doi.org/10.1074/jbc.M116.757393.

44. Lu R, Wu S, Liu X, Xia Y, Zhang YG, Sun J. Chronic effects of a Salmonella type III secretion effector protein AvrA in vivo. PLoS ONE. 2010; 5:e10505. https://doi.org/10.1371/ journal.pone.0010505. 
45. Duan Y, Liao AP, Kuppireddi S, Ye Z, Ciancio MJ, Sun J. beta-Catenin activity negatively regulates bacteria-induced inflammation. Lab Invest. 2007; 87:613-24. https://doi. org/10.1038/labinvest.3700545.

46. McCormick BA, Colgan SP, Delp-Archer C, Miller SI, Madara JL. Salmonella typhimurium attachment to human intestinal epithelial monolayers: transcellular signalling to subepithelial neutrophils. J Cell Biol. 1993; 123:895-907.
47. Liao AP, Petrof EO, Kuppireddi S, Zhao Y, Xia Y, Claud EC, Sun J. Salmonella type III effector AvrA stabilizes cell tight junctions to inhibit inflammation in intestinal epithelial cells. PLoS One. 2008; 3:e2369. https://doi.org/10.1371/ journal.pone.0002369.

48. Blom G. Statistical Estimates and Transformed Beta Variables. (New York: John Wiley \& Sons, Inc.). 1958. 